\title{
XXXVII. On the correction of the compass in iron ships without use of a fixed mark
}

\author{
Sir G.B. Airy K.C.B.
}

To cite this article: Sir G.B. Airy K.C.B. (1878) XXXVII. On the correction of the compass in iron ships without use of a fixed mark, Philosophical Magazine Series 5, 5:31, 267-269, DOI: 10.1080/14786447808639423

To link to this article: http://dx.doi.org/10.1080/14786447808639423

曲 Published online: 13 May 2009.

Submit your article to this journal $[\pi$

Џ Article views: 2

Q View related articles $\square$ 
On the Correction of the Compass in Iron Ships.

at the centre of the ball, at one fifth of the radius from the centre, at two fifths at three fifths at four-fifths at five fifths at a point on the circumference. "

In this figure (6), $0 \mathrm{P}$ represents the initial excess of temperature of the whole ball over that of the stream of water, and $\mathrm{OQ}$, measured along the axis of time, represents 2500 seconds from the commencement of the cooling.

The curves G G G, H H H, I I I, J J J, K K K, L L L, fig. 7, represent respectively the distribution of temperature from the centre to the circumference of the ball at times 100,500 , $1000,1500,2000,2700$ seconds from the commencement of the cooling, $O \mathrm{~T}$ representing the initial difference between the uniform temperature of the ball and the stream of water, and $O R$, measured along the axis of distance from the centre of the ball, representing the radius.

We have to thank three of our students, Messrs. Asano, Fujioka, and Nakano, for assistance rendered in the experiments, and three others, Messrs. Nakahara, Nobechi, and Oshima, for aid given us in the calculation of the Table of the values of $\frac{a}{\tan \alpha}$ for different values of $\alpha$.

January 1878.

XXXVII. On the Correction of the Compass in Iron Stips without use of a Fixed Mark. By Sir G. B. AIRY, K.C.J3., Astronomer Royal*.

[Plate XI.]

T AM indebted to Sir William Thomson for the suggestion 1 that the Compass in an Iron Ship might be corrected for the effects of the Permanent or Polar Magnetism of the ship without use of a fixed mark. On considering the subject, the process here described quickly suggested itself. It is based upon the following assumptions:-

That the effect of the Transient Induced Magnetism may be neglected.

That by means of an auxiliary compass the ship's head may be kept steady on one bearing for a few minutes.

That the magnitude of the actual directive force may be ascertained, in terms of any arbitrary scale (the most con* Communicated by the Author. 
venient expression will probably be, the square of the number of vibrations made in one minute of time), by the vibration, either of the compass-needle if very finely mounted, or by the vibration of a needle suspended by a silk fibre, the compass being removed during this observation.

It is almost unnecessary to say that the apparent bearing of the ship's head as referred to the disturbed compass, or rather the bearing of the disturbed needle as referred to the head-and-stern line of the ship, is to be observed.

The circle represented in the accompanying diagram, $\mathrm{Pl}$. XI. (which, in practice, ought to be made from an engraving, in order that a separate circle may be used for each separate correction of compass) is to be conceived as attached to the ship's deck, with the line $\mathrm{H}$ S parallel to the ship's keel.

Then the operation proceeds as follows:-

The ship's head is to be placed in three different azimuthal directions; the most favourable will be three directions which very rudely divide the horizon into three not very unequal azimuths. In each direction, the magnitude of the actual directive force, and the bearing of the disturbed needle as referred to the head-and-stern line, are to be observed.

In the first observation, let $A O$ represent the magnitude and direction of the actual directive force ; in the second and third observations, let $\mathrm{B} \mathrm{O}$ and $\mathrm{CO}$ represent similar quantities. Take the metallic T-square represented at the bottom of the diagram; apply its graduated edge to the points B and $\mathrm{C}$ so that the numerations of the graduations touching $\mathrm{B}$ and $\mathrm{C}$ are equal (the scale of the graduations is unimportant, all that is required being that they be equal on the right side and on the left side), and draw a pencil along the fiducial edge of the transverse arm, thus describing the line $b c, b c$. Apply the graduated edge in like manner to the points $\mathrm{A}$ and $\mathrm{C}$, and thus describe the line $a c, a c$, intersecting the former line at $P$. The same operation may be performed on $A$ and $B$, describing the line $a b, a b$; but it is not required, as that line will necessarily pass through the point $P$.

Then $O \mathrm{P}$ represents in direction and in magnitude (on the same scale as $\mathrm{AO}, \mathrm{BO}, \mathrm{CO}$ ) the magnetic force which must be introduced for the correction of the compass. For, it is a force which accompanies the ship in all its motions; and its introduction, and its composition with the observed forces $\mathrm{AO}, \mathrm{BO}, \mathrm{CO}$, will produce the resultant directive forces $\mathrm{A} \mathrm{P}, \mathrm{B} \mathrm{P}, \mathrm{CP}$; which, from the nature of the geometrical process, are equal, and will represent the terrestrial directive force, equal in magnitude for the three positions of the ship. 
Sir G. Airy's Correction of the Compass in Iron Ships, without use of a fixed mark.

$\Lambda$
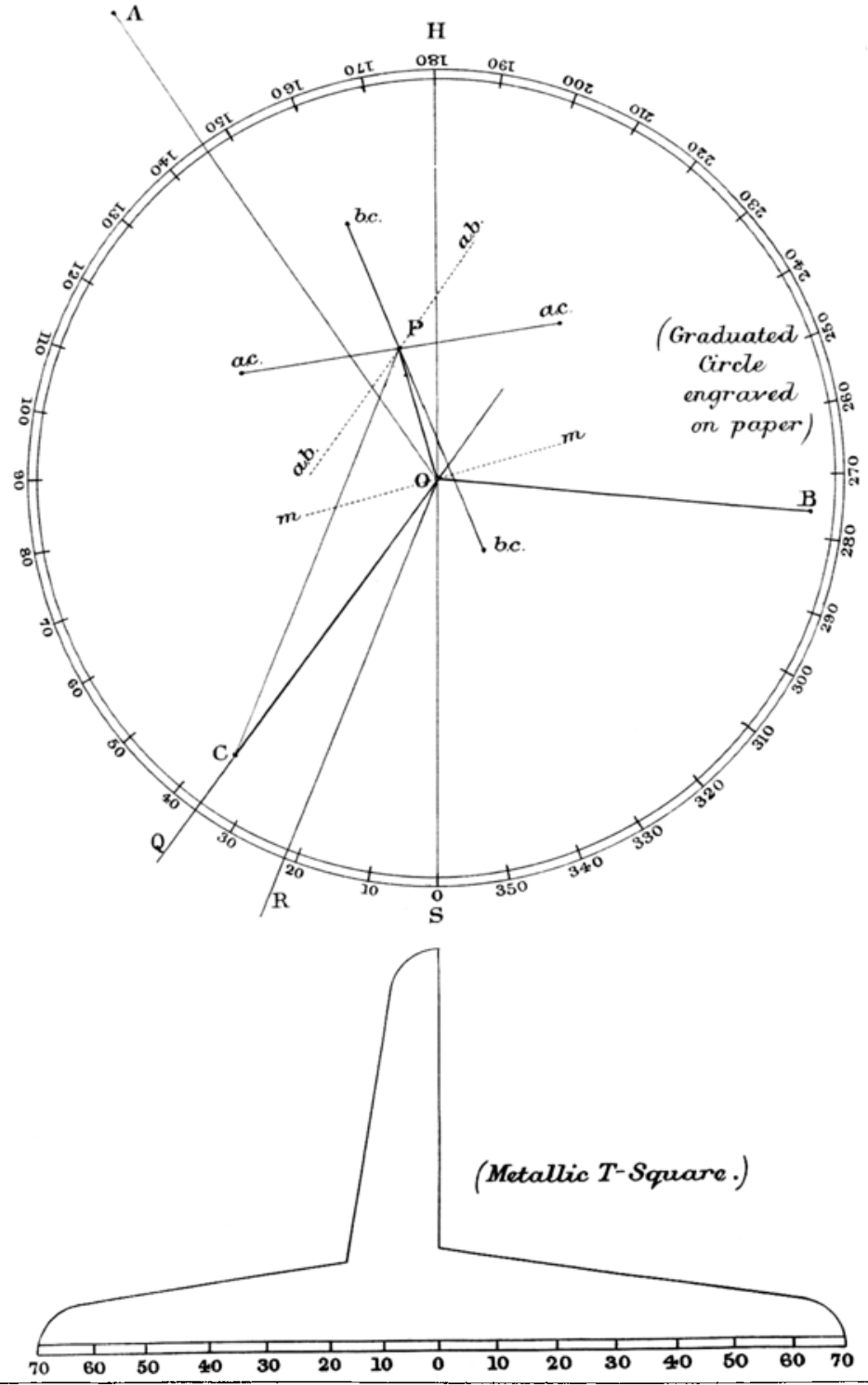
The actual operation of correction will be the following :-

1. The length of the correcting magnet must be parallel to $O P$. If it is to be applied end-on, it must be in the line $0 \mathrm{P}$. If it is to be applied broadside-on (which is preferable) draw the line $m m$ through $\mathrm{O}$ and at right angles to $\mathrm{OP}$ : the centre of the magnet must be in that line.

2. Join $\mathrm{PC}$, and if necessary produce $\mathrm{OC}$ to Q. Draw $O R$ parallel to $\mathrm{PC}$. Then $\mathrm{QO} R$ is the angle through which the direction of the compass-needle is to be changed by the application of the correcting-magnet; and the distance of that magnet is to be changed (always preserving its direction, as already described) till the compass-needle points in the direction $\mathrm{R} O$. Instead of C, A or B might have been used in the same way.

Royal Observatory, Greenwich, March 11, 1878.

XXXVIII. On Permanent Plateau's Films. $B y$ Silvanus P. Thompson, B.Sc. B.A.*

1. THE film-figures, which occupy so large a part of the 1 researches of Plateau t upon the Molecular Statics of Liquids, when prepared with the glyceric fluid prescribed by their discoverer, are of extreme fragility and of short duration. With such a liquid films have been made which lasted ten, twelve, or even sixteen hours in the air, and from fifteen to thirty hours when protected by an external vessel of glass. In one instance $\ddagger$, where chloride of calcium had been added to the liquid, a duration exceeding fifty-four hours was observed. The average duration of the films, especially if they are to be exhibited to a number of persons, is more brief.

No method bitherto described of producing these films in a more durable or permanent form has been quite satisfactory, though there have been several attempts. Of these the writer was not aware when he began the present investigation, though most of them are mentioned in the later chapters of Plateau's work already named. A brief enumeration of these attempts will therefore preface a description of the process now announced for rendering the films permanent.

2. M. Plateau has himself endeavoured\$ to fix the filmfigures by dipping the wire frames into solutions which eva-

* Communicated by the Physical Soziety.

+ Statique expérimentale et théorique des liquides sormis aux seules forces moléculaires. Par J. Plateau. Grand et Leipzic: 1573.

I Plateau, op. cit. vol. i. p. 175 , $\$ 106$.

$\$$ Ibid. vol. ii. p. 119, \$311. 